\title{
Arab metallurgy owes much to meteorites iron -A special regard to Damask saber
}

\author{
Ahmad Bilal \\ Damascus University, Damascus, Syria; bilka@scs-net.org \\ Received 2 January 2014; revised 2 February 2014; accepted 9 February 2014 \\ Copyright (C) 2014 Ahmad Bilal. This is an open access article distributed under the Creative Commons Attribution License, which \\ permits unrestricted use, distribution, and reproduction in any medium, provided the original work is properly cited. In accordance of \\ the Creative Commons Attribution License all Copyrights (C) 2014 are reserved for SCIRP and the owner of the intellectual property \\ Ahmad Bilal. All Copyright (C) 2014 are guarded by law and by SCIRP as a guardian.
}

\section{ABSTRACT}

Ancient Arabs have recognized metallic and mineral ores, including their fluid inclusions which were still considered as a new scientific fields in the 70's last century. They discovered metallic ores (gold, silver, copper), in inhabited areas and in delta and river crosses, using different techniques for exploration and exploitation. Metallic industry flourished during the Islamic period, silver and gold were used as currency for commercial exchanges. Meteorites were also recognized by Ancient Arabs. They collected them in the deserted areas, and used them for arms manufacturing, as sabers and daggers. The more famous of these arms is the Damask saber steel, known reputedly Jaohar. It has an extraordinary mechanical properties, and exceptional sharp cutting edge. The Jaohar blades were forged directly from fall meteorites, at temperature of $80^{\circ} \mathrm{C}$, using a sophistical thermomechanical of forging, annealing to refine the steel, and giving it this exceptional quality and superelastic behavior. Meteorites using by Ancient Arabs come back to 400 years ago, as confirmed by a recent research on two meteorites samples, presented in Aleppo museum, found in Ras Shamra, and Umm El Maraa, in Syria.

\section{KEYWORDS}

Arabs Science Heritage; Ores Metallic; Meteorites; Jaohar Saber

\section{INTRODUCTION}

The scientific literatures learn about the Arab contri- bution in the sciences domain, especially, minerals, gemstones, and metallurgy [1]. Al-Birouni, the great Arab scientist, was the first person to identify and describe fluid inclusions [2]. It happens that at this time (70's of the last century), these were still considered as a new scientific fields, only studied by a handful of researchers [3].

Therefore an interest research was lanced to know more about the contributions of the ancient Arab civilization to modern science, particularly in the fields of exploitation and manufacturing of metals and mineral ores [4], with a special regard to the meteorites iron and Damask saber.

The research on meteorites and theirs parent with the Damsk saber, using a portable analyzer, Niton XL 3t-900, results of recent meteorite exploration in Syria, done in the framework of a cooperative scientific project between Damascus University and the Pierre and Marie Curie University of Paris-France [5].

In this paper, we will present briefly the heritage of Ancient Arabs in these fields during the pre-Islamic and Islamic periods, through the identification of most famous ores mines by visiting most of the Arab country and their literature treasuries, the proof that Ancient Arabs did recognize and collect meteorites in the desert area, and use them for manufacturing tools and arms, especially the Damask saber, giving a brief information on the characteristics of this saber.

\section{ANCIENT ARAB METALLURGIC AND ARCHAEOLOGY CONTRIBUTION}

The heritage of ancient Arabs in metallic ores is recognized since the early times, during the pre-Islamic and Islamic periods $[4,6]$. Remnants of numerous ores mines witness extensive commercial change at this time. Less known is the fact that the famous Damascus blades may have been made of meteorite iron. 


\subsection{The Pre-Islamic Period Owes}

During the pre-Islamic period, metallic ores were discovered mostly in inhabited areas of the Arabian Peninsula (today’s Yemen, and Hijaz in eastern Saudi Arabia) $[7,8]$. At that time, Arabs knew and excavated gold, both as an ore and a metal, in the north of Sabaa, Hijaz, and Najran. They used to exchange it for silver and cooper with neighboring countries, especially Yemen [8,9]. Tools used to explore and exploit gold from the Mahd Al Zahab mine have been found in Saudi Arabia (Figure 1). During those old times, lead was used to cement stones with pillars to build citadels [10]. This activity made from Arab region, the most famous archaeological re- servoir in the world.

\subsection{The Islamic Period Heritage}

During the Islamic period, the metallic industry flourished. Ibn Khaldun mentions that the early Muslims used silver and gold as currency for commercial exchange between the states and emirates, in addition toother precious stones [11]. They used to pay gold ransoms for POWs, whether soldiers or commanders (as in the case of the conquest of Carthage). In Egypt they found gold in Ancient Pharaonic temples [12]. They knew then how to excavate gold ore from rivers and desert sands, especially in Wadi Al Aallaki, 600 k. m.

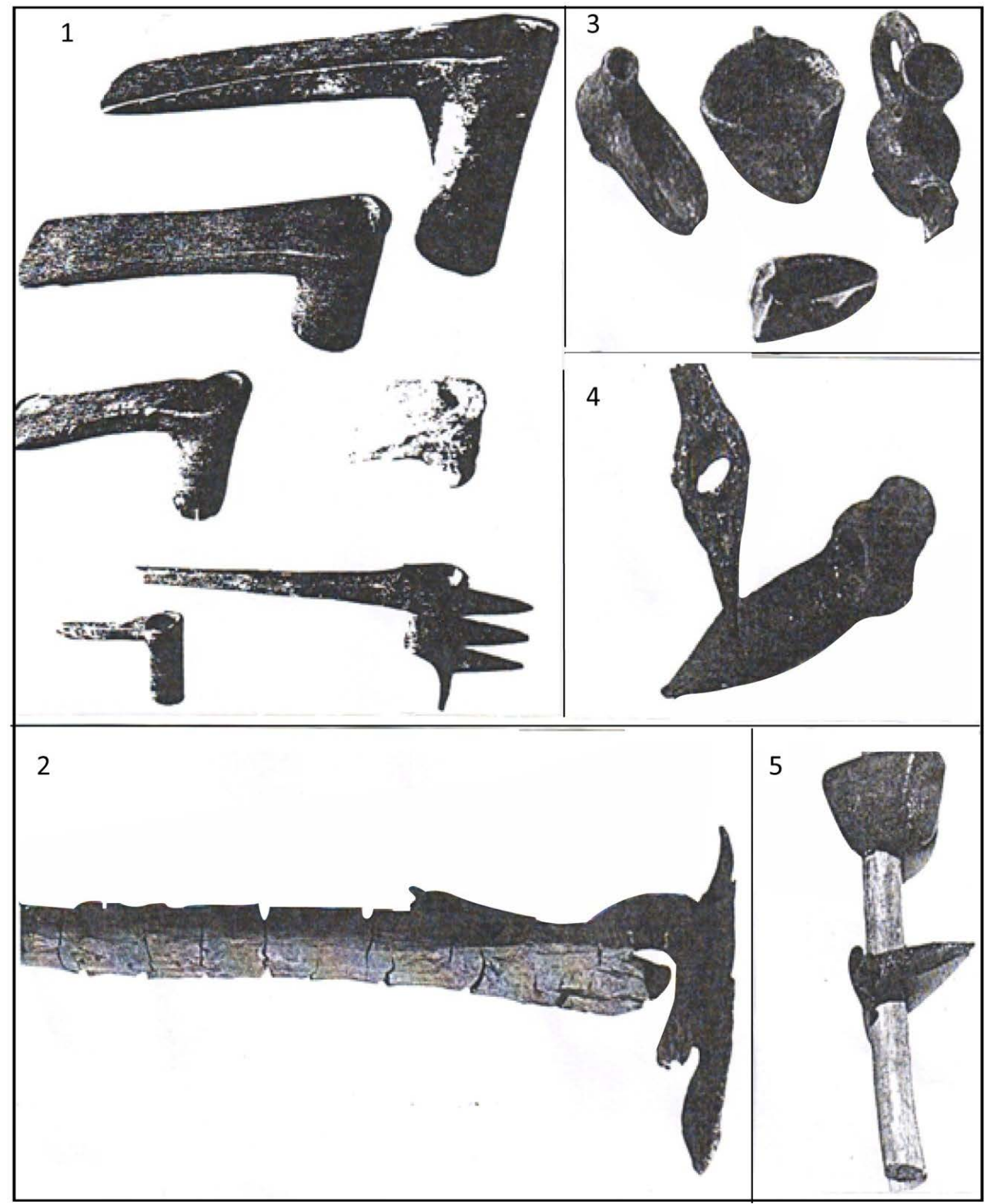

Figure 1. Used tools by ancient Arabs in exploration and exploitation of metallic and mineral ores: 1 - Hatchets, 2-Belle, 3-Candles, 4-Heads of hatchets, 5-Hammer [8,10]. 
from Aswan, as mentioned by the famous Arab geographer Al Idrissi [13]. He described how they use to prospect for gold by locating its glimmer when the moon was dimmed. They then washed sand to separate the gold. Several rivers were famous: Sifri, Tajo, and Hadra in Andalusia, and, Sakiat Wadi Al Zahab in Africa. They used to prospect for gold in deltas and river crosses. For silver, they would locate the ore in underground caves using candles until they went off for lack of oxygen. Maghrebian regions have exploited the ore mines using the rooms and pillars method (Figure 2). All Arab regions, have known, exploited and used metallic and mineral ores, using the advanced technology constituted of waterwheel to get upon the water, the support pillared for the mine rooftop, tools for crashing the ore, and for water transporting (Figure 3), especially North Africa [14-17]. Egypt was the most famous for precious stones.

\subsection{Ancient Arabs Ores Mines Occurrence}

A long research in the literature has permit to me to calculate (107) ancient ores mines in the Arab countries (Table 1). They distributed as following: /37/ gold, /4/ silver, /5/ cooper, /11/ lead, /15/ iron, /35/ mixed (Table 1).

\section{ARAB HERITAGE IN METEORITES MANUFACTURING-DAMASK SABER}

Meteorites are small parts forms stars which fall away and crash the earth. The peoples see them in the space, and they look for them in the erase areas. They collect them, especially in the deserts, and none cultivate areas, where they can are preserved.

Ancient Arabs have recognized meteorites and collected them in the deserted areas, and use them for arms manufacturing.

\subsection{Damask Saber Characteristics}

The more famous of these arms are sabers, and daggers, very known in Blade Ash Sham countries (Syria, Iraq, Palestine, Lebanon, Jordan).

The ancient Damask saber steel, known as Damask

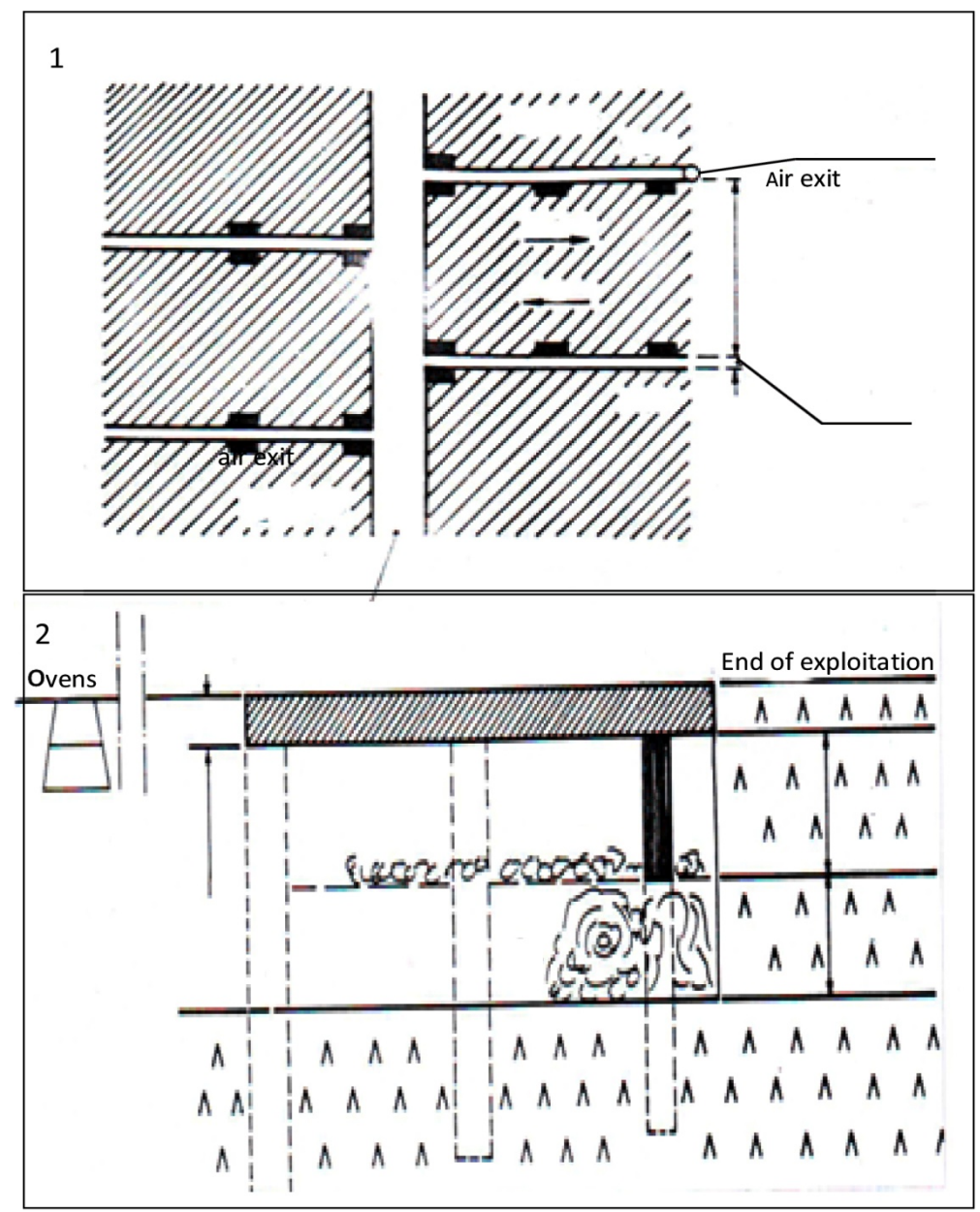

Figure 2. Method of rooms and pillars to exploit the mines in Morocco (1), and its details (2) [4]. 


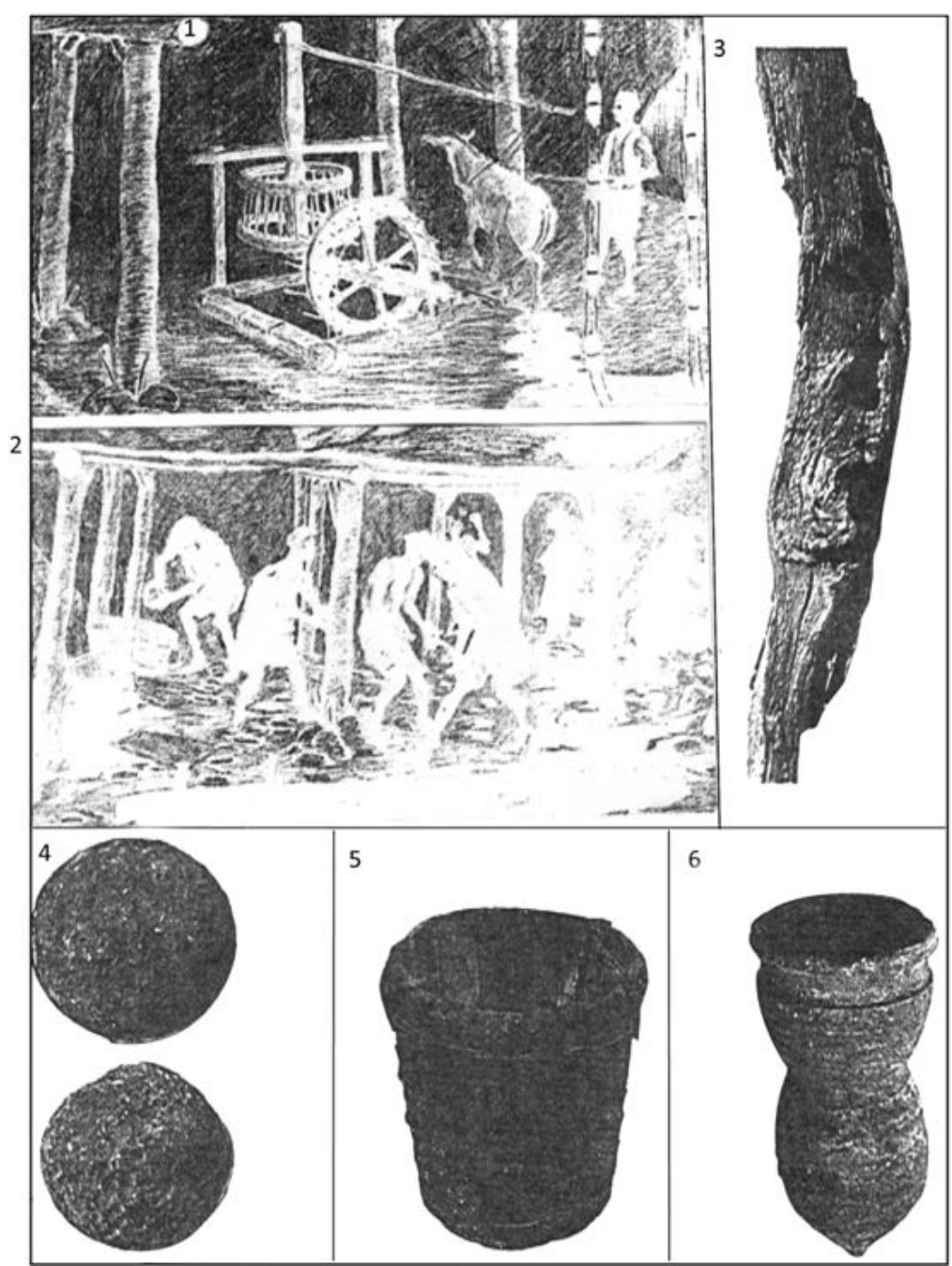

Figure 3. Schematic approach to exploit a min of metallic ore and technology of waterwheel to get upon the water $(1,2)$, support pillared for the min rooftop (3), and some types of used tools for crashing the ore (4), and for transporting water $(5,6)[8,10]$.

Table 1. Ancient Arabs ores mines occurrence. The digit indicates the number of mines of the relevant ore in each country.

\begin{tabular}{|c|c|c|c|c|c|c|c|}
\hline Country & Iron & Zinc & Cooper & Lead & Gold & Silver & Mix \\
\hline Algeria & 1 & - & - & 3 & - & - & 1 \\
\hline Egypt & - & 1 & 8 & 1 & 20 & - & 2 \\
\hline Iraq & 2 & - & - & - & - & - & 1 \\
\hline Jordan & 1 & - & 3 & - & - & - & - \\
\hline Morocco & 6 & - & 9 & 4 & - & 2 & 3 \\
\hline Mauritania & - & - & - & - & 1 & - & 1 \\
\hline Saudis Arabia & 1 & - & - & - & 2 & 2 & 9 \\
\hline Somalia & - & - & - & 1 & - & - & - \\
\hline Sudden & - & - & 1 & - & 13 & - & 1 \\
\hline Syria & 1 & - & - & - & - & - & - \\
\hline Tunisia & 2 & - & - & 2 & - & - & - \\
\hline Yemen & 1 & - & - & - & 1 & - & - \\
\hline
\end{tabular}


Saber, or more reputedly Jaohar, has features not found in European steels [18]. It has an extraordinary mechanical properties, and exceptionally sharp cutting edge. The Damascus saber blades could be forged directly from fall meteorites at temperature of $800{ }^{\circ} \mathrm{C}$, using a sophisticated thermomechanical treatment of forging and annealing, to refine the steel to its exceptional quality, giving the meteorite its fine-grained, and superplastic behavior. A recent study on the Damask saber steel, has detected a carbon nanotubes, indicating an age of 400-year age [18].

\subsection{Syrian Meteorites and Damask Saber Parent}

During a recent scientific project between the Pierre and Marie Curie University in France, and the Damascus University in Syria, on the meteorites in Syria, two meteorites samples, in the Aleppo museum, were analyzed in place using a portable analyzer, Niton XL3t-900 [5].

Ras shamra sample: It is a meteorite Hammer d'Ugarite, from the Bronzian age, found in Ras Shamra, in the twentieth years (Figure 4). XRF analyses results of the iron blade, at different locations, are reported in Table 2. The blade is made of iron with a significant Ni content, in the range from $1.7 \mathrm{wt} \%$ to $7.6 \mathrm{wt} \%$, and an average value of $4.33 \%$. This can be compared with the range of $5 \%$ -
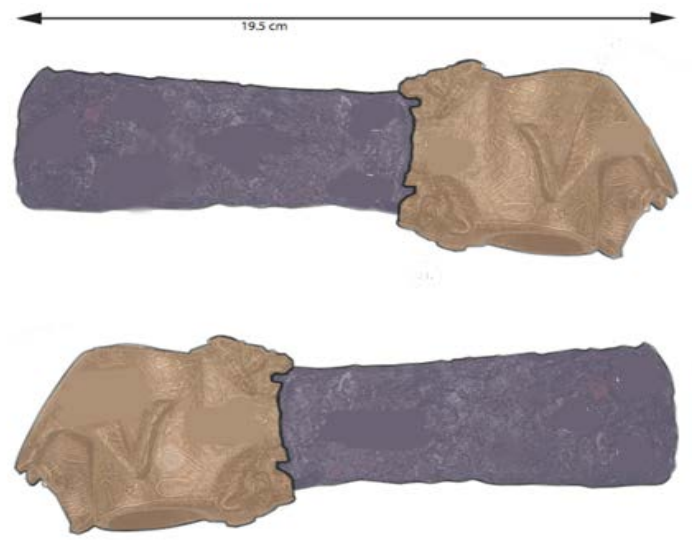

Figure 4. Meteorite Hammer d'Ugarite of Ras Shamra.

Table 2. Comparison of RS Hummer d'Ugarite analyses with data for iron meteorites taken from the literature on fresh samples, and variably weathered samples analyzed by XRF on one hand and terrestrial mantle value on the other.

\begin{tabular}{ccccc}
\hline & $\mathrm{Ni}$ & $\mathrm{Co}$ & $\mathrm{Ni} / \mathrm{Fe}$ & $\mathrm{Ni} / \mathrm{Co}$ \\
\hline RS & $\mathbf{4 . 3 3}$ & $\mathbf{0 . 4 7}$ & $\mathbf{0 . 0 4 5}$ & $\mathbf{9 . 1 7}$ \\
Iron XRF & $4.5-16$ & $0.41-0.78$ & $0.05-0.19$ & $9-20$ \\
Irons literature & $6-17$ & $0.36-0.74$ & $0.07-0.21$ & $11-24$ \\
Mantle & 0.20 & 0.010 & 0.025 & 19 \\
\hline
\end{tabular}

20\% (average 7\%) for iron meteorites. The low values of RS result from oxidization, known to be impoverished in Ni. Thus the Ni signal is partly absorbed by the surface layer of iron oxide leading to an average apparent composition lower in Ni than the fresh metal. This phenolmenon has been checked by analyzing, with the same XRF analyser, iron meteorites with different weathering stages. Consequently it is logical to consider the correlation between the $\mathrm{Ni} / \mathrm{Fe}$ and $\mathrm{Ni} / \mathrm{Co}$ of iron meteorites. The range observed for RS overlaps the range observed for iron meteorites. Therefore the blade of Ras Shamra axe is made from meteoritic iron.

Umm El Marra sample: It is a meteorite alter Pendant, rusted iron (a small residual metallic iron of $25 \mathrm{~g}$ ) (Figure 5), from the Bronzian age, found by the team led by Glenn Schwartz and Hans Curvers 2000. The analytical results are reported in Table 3 . The $\mathrm{Ni} / \mathrm{Fe}$ ratio is mostly the representative coefficient to checks the meteorites origin. This ratio registers a high value (0.02 to 0.1$)$ whereas iron from ore is in a much lower range $(<0.001)$. The results in Table 3, are therefore quite obvious: all analyses present ratios in excess of 0.0 , between 0.013 0.035 . Exempting any contaminations possibilities: addition of Ni from the surrounding to Ni free metal, or selective loss of Ni from a Ni-rich metal. The sample therefore had a high $\mathrm{Ni} / \mathrm{Fe}$ ratio typical of meteoritic iron.

Damask saber (Jaoher): The chemical composition average of the Damask saber, through several analyses of some sabers from the fifteenth century, and from several positions of a saber of $1448 \mathrm{AC}$, as written on the blade of the saber (Figure 6), is presented in Table 4.

\subsection{Origin of Damask Saber}

These values, especially the average ratio $\mathrm{Ni} / \mathrm{Fe}(=0.029)$,

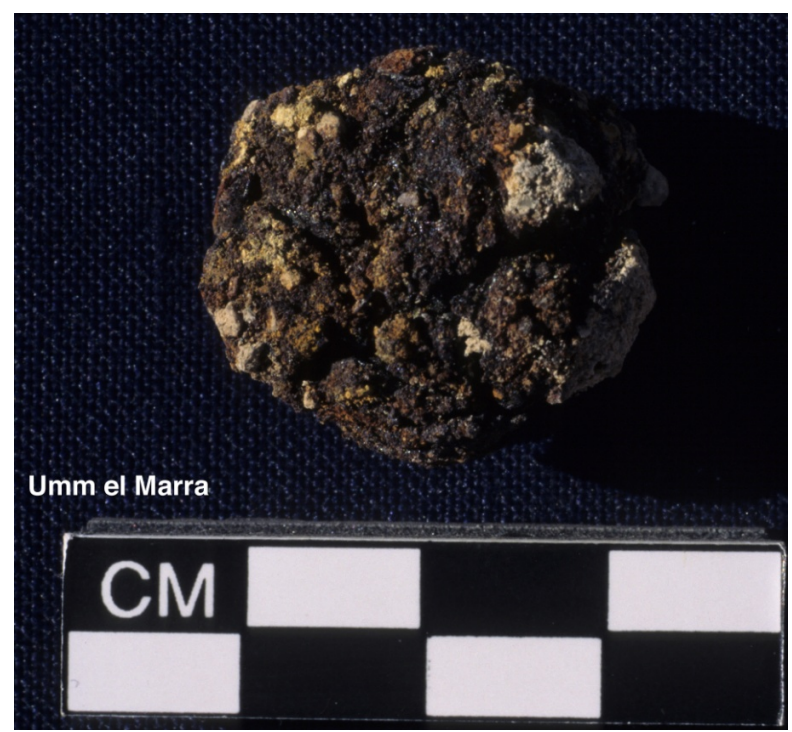

Figure 5. Meteorite alters Pendant of Umm El Marra. 
Table 3. Analytical results (wt\%) of meteorite alters Pendant of Umm El Marra (BDL = below detection limit).

\begin{tabular}{cccccccc}
\hline & A & B & C & D & E & F \\
\hline Balance & 43.18 & 44.16 & 50.22 & 44.71 & 47.19 & 30.18 \\
$\mathbf{F e}$ & 46.21 & 48.81 & 39.18 & 46.50 & 42.83 & 65.5 \\
$\mathbf{N i}$ & 0.58 & 1.29 & 1.36 & 0.66 & 0.84 & 2.03 \\
$\mathbf{C o}$ & 0.21 & 0.25 & 0.27 & 0.19 & 3.04 & 0.26 & 0.31 \\
$\mathbf{S}$ & 3.67 & 0.62 & 0.026 & 0.02 & 0.22 \\
$\mathbf{N i / F e}$ & 0.013 & 5.12 & 5.11 & 3.51 & 3.20 & 0.03 \\
$\mathbf{N i / C o}$ & 2.70 & 95.13 & 91.32 & 95.10 & 91.95 & 9.56 \\
Total & 93.85 & & & 97.79 \\
\hline
\end{tabular}

Table 4. Analytical results of the Damask saber of Figure 6A (in a, b, c, and d locations), and for different sabers (B, C, D).

\begin{tabular}{cccccccccc}
\hline & & $\mathbf{N i}$ & $\mathbf{C o}$ & $\mathbf{F e}$ & $\mathbf{S}$ & $\mathbf{N i / C o}$ & $\mathbf{N i / F e}$ & Balance & Total \\
\hline $\mathbf{A}$ & $\mathbf{a}$ & 1.32 & 0.21 & 45.18 & 0.68 & 6.30 & 0.030 & 46.12 & 92.83 \\
& $\mathbf{b}$ & 1.16 & 0.25 & 41.12 & 1.12 & 4.64 & 0.028 & 48.53 & 91.06 \\
& $\mathbf{c}$ & 1.28 & 0.24 & 43.35 & 0.83 & 5.33 & 0.030 & 47.18 & 92.05 \\
& $\mathbf{d}$ & 1.41 & 0.29 & 44.16 & 1.18 & 4.86 & 0.032 & 46.23 & 91.99 \\
$\mathbf{B}$ & & 1.34 & 0.22 & 47.18 & 0.62 & 6.10 & 0.030 & 45.17 & 93.93 \\
$\mathbf{C}$ & 1.29 & 0.23 & 45.43 & 2.04 & 5.61 & 0.028 & 46.61 & 93.56 \\
$\mathbf{D}$ & 1.23 & 0.19 & 48.19 & 0.42 & 6.47 & 0.025 & 45.29 & 94.90 \\
\hline
\end{tabular}

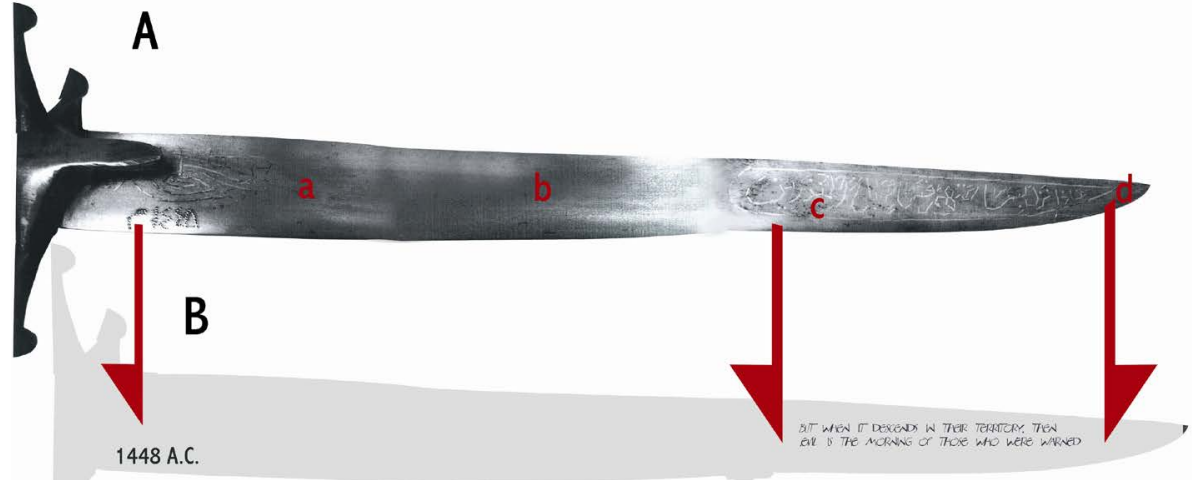

Figure 6. Photo a real Damask saber from 1448 AC (A), and a scheme showing the date, and the verse in Arabic, a, b, c, d, and locations of chemical analysis.

are in good similarity with the two upon analyzed meteoritic sample, from Umm El Marra, and Ras Shamra, taking in consideration the upon indicated contingencies factor of those samples. The meteoritic parental with the Damask saber is also indicated by the verse /177/ of Assafat, Surat $/ 37 /$, written on the saber blade in Arabic, saying: But when it descends in their territory, then evil is the morning of those who were warned. Which descend, after this upon verse, are meteorites.

\section{CONCLUSIONS}

Ancient Arabs have an important contribution in the civilization of exploration, and manufacturing of metallic and mineral ores. They have discovered and used the 
most of the metallic ores, through more than /113/ ore mines, distributed in /13/ Arab countries.

During the Pre-Islamic and Islamic period they recognized, and exploited gold, silver, copper, lead, salt, etc. and they used advanced methods to exploit these ores. They used big stones to build citadels which made the Arab region the most famous archaeological reservoir in the world.

They especially known and used meteorites to manufacturing arms. The Damask saber, named Jaohar saber, is, by its mechanical properties and superelastic behavior, the most famous world saber. The parental meteoritic, proved in this paper, with this arm must be confirmed by more scientific investigations.

This advanced role not to remember that ancient Arab role, but to incite us to feedback this role, and to contribute more in the modern civilization. Thus they can give to their ancient civilization the alive.

\section{REFERENCES}

[1] Al Farabi (1953) Kitab Ihsa aluloum. The book of the Sciences Enumeration and translated by A. Gonzelez. 870-950.

[2] Hakim, M.S. (1989) Al Birouni’s book on mineralogy. Pakistan Hijra Council, Islamabad.

[3] Bilal, A. (1978) Fluid inclusions in mantelic xenolithsGeotectonic implications. Doctorat d'Etat Thesis, University of Paris, Paris.

[4] Mohamadi, A. (1983) Techniques of rooms and pillars used in ancient Moroccan mines. Arab Mineral Resources Journal, n 3, 41-50.

[5] Jambon, A. and Bilal, A. (2010-2012) Rapport de coopération. UMPC, Université de Damas sur les Météorites in Syrie, Paris.
[6] Jamil, A.K. (1983) Metallurgy of ores and mineral separation in Iraq. Arab Mineral Resources Journal, n 3, 105113.

[7] Ministry of Petrol and Metallic Resources (1974) Map occurrence of ores mines in the Arabic dorsal. Ministry Deputy for Metallic Resources, Saudi Arabia.

[8] Adly, Ab. M. A. (1979) General outline of the geology and mineral occurrences of the Red Sea Hills. Bulletin No. 30, Ministry of Energy, Geological and Mineral Resources Department, Sudan.

[9] Alomar, K. (1983) Ancient mines activities in Jordan. Journal Arab Mineral Resources, n 3, 95-102.

[10] Bilal, A. (1983) Ancient Arab legacy in the exploitation and manufacturing of metallic ores. Arabe Minerales Resources Journal, n 3, 89-94.

[11] Ibn Khaldun (1332-1406) Chronique général, procédé de prolégomènes. Ibn Khaldoun.

[12] Afieh, M.S. (1983) Min activities in Egypt and Sudden during the successive civilization. Arab Mineral Resources Journal, n 3, 51-69.

[13] Al Idrissi (1099-between 1165-1186) His book Nozhat al moshtak vi ikhtrak al afak, and his maps.

[14] Al Saadi, M. (1983) Map occurrence of ancient ores mines in morocco. Ministry of Energy, Morocco.

[15] Rosenberger, B. (1970) Les vieilles exploitations minières et les centres métallurgiques du Maroc. Essai de carte historique. Revue de Géographie du Maroc, no17 et 18.

[16] Youssef, B. and Sassi, S. (1983) Metal manufacturing during the history in Tunisia. Arab Mineral Resources Journal, n 3, 133-139.

[17] Gsells (1928) Ancient mines exploitation of Northern Africa. Morocco Institute of History High Studies Congress.

[18] Reibold, M., Paufler, P., Levin, A.A., Kochm W., Patzke, N. and Meyer, C. (2006) Materials: Carbon nanotubes in an ancient Damascus saber. Nature, 284-286. 